\title{
Research on the application of the internet of things in Reverse Logistics Information Management
}

\author{
Yuexia Gu, Qingqi Liu \\ Liaocheng Vocational And Technical College, Liaocheng, Shandong, (China) \\ flybirdsll@yeah.net
}

Received: March 2013

Accepted: April 2013

\section{Abstract:}

Purpose Combined the current situation with the development trend of reverse logistics, the article focus on the research of Internet of Things application in the reverse logistics information management, starts with the study of reverse logistics information system, and describes the system structure and system process in applying Internet of Things in reverse logistics information management, finally brings forward the constraints like management and economic ones in applying the technology to the system.

Design/methoddogy/approadr By analyzing the current situation of reverse logistics information system, utilizing literature research methods to put forward characters of reverse logistics information system, and expanding the previous studies on Internet information transmission, we gradually establish the reverse logistics management information system on the basis of the application of Internet of Things.

Findings: Through applying the Internet of Things in the reverse logistics system, we can build a complete close-loop logistics system by linking both extreme ends of positive and negative logistics. Besides, the system will be engaged in data mining in backflow prediction data and reprocessing data at regular and irregular intervals. Moreover, advice will be provided to design, purchase, manufacturing and customer service departments for their reference so as to promote respective business. 
Research application and limits: This paper focuses on how the enterprise should apply the Internet of Things technology in reverse logistics, and how to build this system in detail and what the flow planning is made. This thesis is only limited to the analysis of constraints impeding the development of the reverse logistics MIS, including management constraints, economic constraints, hardware technology, data security and rights management constraints. Detailed solutions to address these problems will be put forward in the further research.

Originality/value: The value of this article is that building a complete close-loop logistics system by linking both extreme ends of positive and negative logistics. Besides, the system will be engaged in data mining in backflow prediction data and re-processing data at regular and irregular intervals.

Keywards: reverse logistics, internet of things, information system

\section{Introduction}

Nowadays, as people are gradually aware of the contributions that reverse logistics has made to environment and economy; enterprises are paying more attention to the promotion of reverse logistics. However, reverse logistics is different from forward logistics; the difficulties in application have aroused wide attention. The reason that leads to the delay in application of reverse logistics is heatedly debated, and the academy field holds different views about it, but it is an acknowledged fact that collecting reverse logistics information in difficult. The reason is that reverse logistics involves uncertainty of all attributes in products, and this demands diverse reverse logistics processes. If we ignore the uncertainty and use the same process to treat all products, then we will waste many recyclable, valuable products, thus reducing the profits created by reverse logistics in a large scale. To make up for it, we need to know the information of different products in the whole close-loop supply chain promptly and accurately. After Daugherty and Jalal Ashayeri confirmed that information system and reverse logistics performance was positively correlated through empirical study in 2002 and 2005, relevant research is more than active (Daugherty, Richey, Genchev \& Chen, 2005; Ashayeri \& Tuzkaya, 2010). Thus, in implementing reverse logistics, we must absorb reverse management information system that can both record product life cycles vertically and record product attributes horizontally, helping enterprises improve decision management and efficiency of business operations. 


\section{Research summaries and characteristics of reverse logistics management system}

\subsection{Current situation of existing literature}

Researchers have carried out studies on tracking reverse logistics product for a long time, and quickly expand to the tracking of information on product life cycles. Thierry Salomon, Van Nunen and Van Wassenhove (1995) suggested that putting sensors in products to record all kinds of information in their life cycles in 1995 and 1998 to make logistics decisions. This research method is of great importance to information tracking $f$ reverse logistics, but due to the reason like technology and cost, it didn't get promoted at that time. Later, some researchers raise the idea to establish dynamic information network database based on internet product remanufacturing, which can record all the information about the products and provide to the usage to all the member enterprises in the supply chain. The most difficult part of this method is gaining and updating of key data involved.

Since the establishment of Auto-ID by Massachusetts Institute of Technology, the research in "Internet of Things" has got wide attention from related fields and researchers (Miorandi, Sicari, De Pellegrini \& Chlamtac, 2012). This center has provided an ideal platform for data sharing, updating and collecting in reverse logistics information management. Among them, RFID has features that far exceeds those traditional data capture methods, like far distance, multi-goals, rapid identification without touch, especially it can label every product, not the traditional way using bar codes to trace the categories, it even brings possibility to keep track of every product life cycle according to the demand of reverse logistics information system (Asif, 2011; Jamshidi, 2011; Lambert, Riopel \& Abdul-Kader, 2011).

Due to the excellent properties of it, RFID entered into supply chain management field quickly. In 2003, Wal-Mart announced to promote RFID application, bringing RFID to the field of reverse logistics. Then researches in solutions of data tracking and collection begin to surface. For example, in Zhiduan Xu's research to reverse logistics for electronic product, he put forward the idea to build an information sharing platform for electronic waste recovery supply chain through electronic product code (Zhiduan, 2005). That's why Internet of Things is established, solving problems of reverse logistics. Although most researchers support using "Internet of Things" technology in reverse logistics, but the study is still not deep enough in how to apply in reverse information system and how to provide support for evaluating, collecting and remanufacturing reverse logistics products.

\subsection{Characteristics of reverse logistics information system}

An enterprise's vast management system includes the reverse logistics MIS, which bears unique characteristics apart from general information systems. 
First, high information reliability. Information resources are core and vital to an enterprise's operation. Because there is some uncertainty about the property of products in the reverse logistics management, it is up to management personnel's personal understanding of the relevant information to decide how to deal with particular reverse logistics products. In a word, the core element of reverse logistics management is information system.

Second, high complexity of data maintenance. When it comes to general MIS, products' information after their sale is not needed any more, and data of these products hardly changes. However, in the reverse logistics MIS, data deletion is not on the basis of time, instead, data can be different as products change, thus contributing to an increase of the complexity of data maintenance.

Third, broad time-tracking span. In the reverse logistics management system, information time span covers the whole life cycle, which is also the basis of a circular economy. Within the life cycle, many products have a life span of more than ten years or even many decades, therefore, how to keep an accurate and uninterrupted record of data during such a long period is an issue awaiting urgent attention in the reverse logistics MIS.

Fourth, diversification of recording properties. In the reverse logistics MIS, the properties of recorded products are diversified, and are intimately connected to products' types. The ultimate objectives of reverse logistics are to recycle resources and reuse backflow products. Therefore, many aspects should be taken into consideration, which leads to extremely diverse information properties. An increase of product information properties has an immense influence on the complexity of storage and data management.

Fifth, high information dispersion degree. Subjects of product information are very diverse in the reverse logistics process in that apart from factory information, product information mainly covers that in transportation, distribution and retailing and consumers, all of which make up the lower reach of the supply chain. Therefore, much product information, especially concerning the customers, are diverse in location, and are not concentrated at all. Consequently, information collection becomes more difficult than forward logistics.

As far as reverse logistics is concerned, information system bears a greater significance than regular management activities in an enterprise, but its unique characteristic makes it rather difficult to establish a reverse logistics MIS. Some companies have developed some reverse logistics MISs, for example, the American specialized reverse logistics management company Genco has used the reverse logistics processing software to deal with consumers' returning goods. However, current reverse logistics MIS is far from meeting authentic needs of reverse logistics in that it is involved in the tip of the iceberg. Thus, this field has become a hot issue in the research of reverse logistics. 


\section{The establishment of the reverse logistics management information system (MIS) based on the application of the Internet of Things technology}

\subsection{Function and structure of the system}

Based on characteristics of the reverse logistics management information system (MIS), some scholars have been engaged in research on the Internet. For example, Yanxia Cheng and Hui Yue hold that function consists of information sharing, transportation, returning merchandise, inquiry and backflow products management and so forth. In addition, they also think that main participators range from different reaches of enterprises along the supply chain to final clients (Yanxia \& Hui, 2005). However, they do not carry out in-depth discussion on information collection, which is precisely the key and difficult aspect of reverse logistics MIS. Therefore, some researchers advocate building a reverse logistics MIS based on the Internet of Things. Yet there is a lack of maneuverability in detailed reverse logistics operation in that they equal the structure of this information system to that of the manufacturers and vendors (Govindan, Palaniappan, Zhu \& Kannan, 2012; Senthil, Srirangacharyulu \& Ramesh, 2012; Kiritsis, 2011).

This paper will put forward establishing the reverse logistics MIS with the application of Internet of things of things technology, from the perspective of building the supply chain by core enterprises and on the premise of extending producers' responsibilities to the lower reach of enterprises along the supply chain. This system incorporates final clients and other participators along the whole downstream supply chain, and extends to the reverse logistics management by core enterprises. Built on the basis of the Internet of Things technology, this system comprises four main functions including data tracking and collecting, backflow products processing decision support, backflow resources re-utilization, and data initialization information management. Moreover, this system comprises two databases. The first one is product information database, and the other is reverse logistics backflow product decision-making database, which has been processed and mined by the model and method bases. Just as the Figure 1 illustrates.

In the reverse logistics MIS based on the application of Things of Internet technology, the product information database incorporates data ranging from production, consumption, to the former lifecycle of backflow products. Specifically, the database is composed of two parts: relevant data during the production and that after products are transported from the company. The former refers to initial material information of products in that data can be properly collected and recorded and directly managed by the enterprise itself during the production within the company. In the contrary, the latter refers to the data collected during the processes of sale of products, customer purchase, utilization and after-sales maintenance from their being transported to being recycled. The data from the exterior is hard to be collected and leads to a week preliminary research, but it is essential for reference in reverse logistics processing of recycled products. Thus, data in the latter part should be collected through the 
Internet, promptly recorded into the database of the enterprise, and included with the initial material information of products to real-time status information, namely, the product information database.

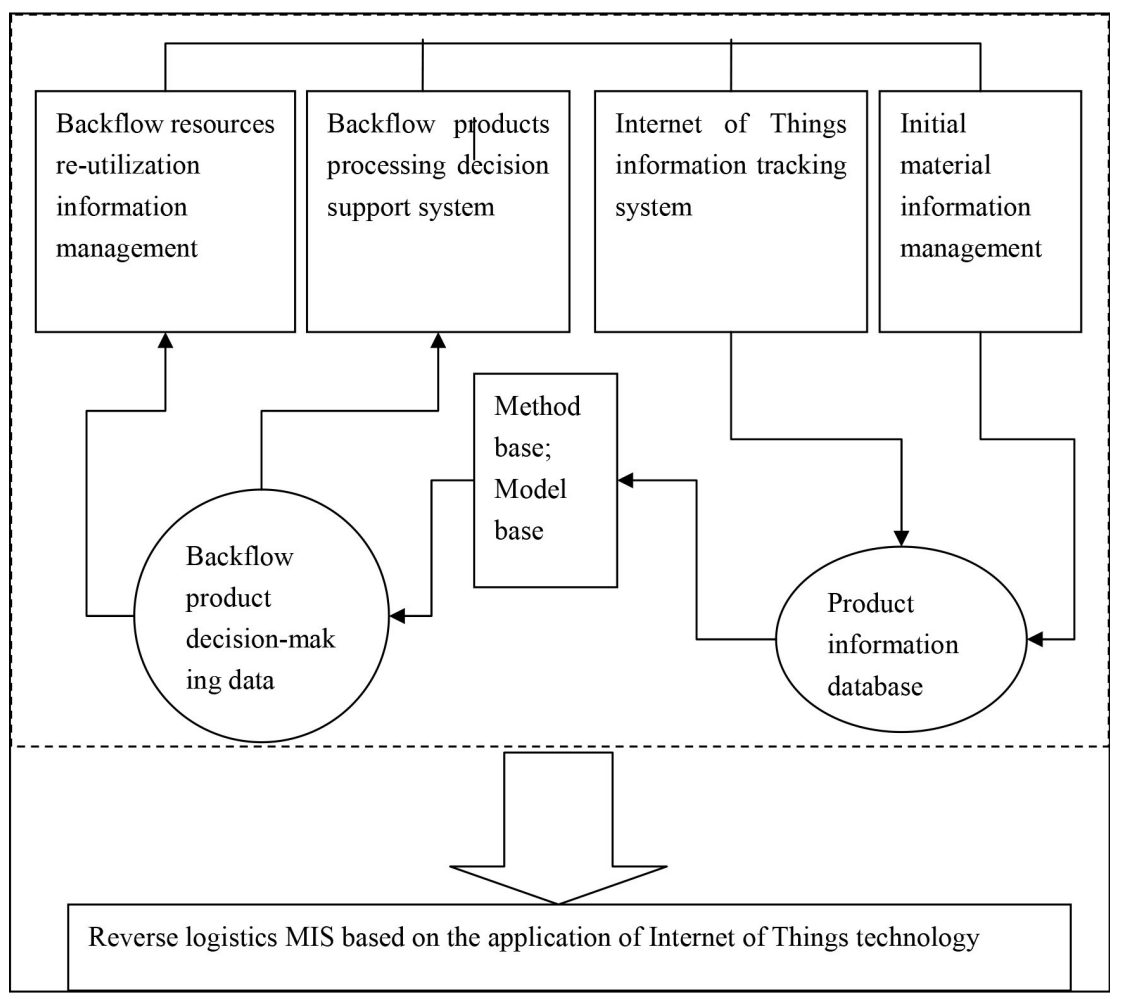

Figure 1. Reverse logistics MIS based on the application of Internet of Things technology

When a product returns to the reverse logistics processing department for some reason, both the equipment manufacturer and the independent third-party logistics service supplier can obtain all relevant information from its production to recycling through accessing to the relevant server according to the product's network storage "address". On this basis, all the relevant data in the product information database will be further processed and mined via the means in the MIS driving method base and models in the model base. Consequently, backflow product decision-making data will be produced and can then be taken by reverse logistics management department for reference in deciding how to deal with this product. This is what we call backflow product processing decision-making support system.

With the progress of introducing the circular economy, supply chain management is no longer limited to the positive open-loop supply chain, but is also open to positive and negative closeloop supply chains. Besides, the upgrading of the supply chain should be built on the basis of the close-loop supply chain as well. Therefore, through analyzing relevant data in reverse logistics, reference can be provided for the design of product, its production as well as raw material purchase. Naturally, resource and energy consumption can thus be reduced in the later life-cycling period, and the goal of building a circular economy can be reached. This is what we call backflow resource re-utilization management. Like initial material information which is an interface between downstream forward logistics and reverse logistics, backflow 
resource re-utilization management is an interface between the upstream forward logistics and reverse logistics. Therefore, a complete close-loop logistics system can be established through linking them.

\subsection{System flow}

In the reverse logistics information system based on the Internet of Things, it is necessary to record the product's information during its whole life recycling period. Relevant information should be recorded through the Internet of Things into the enterprise's Physical Markup Language (PML) server and managed collectively by core enterprises along the supply chain. The flow chart is as Figure 2 illustrates:

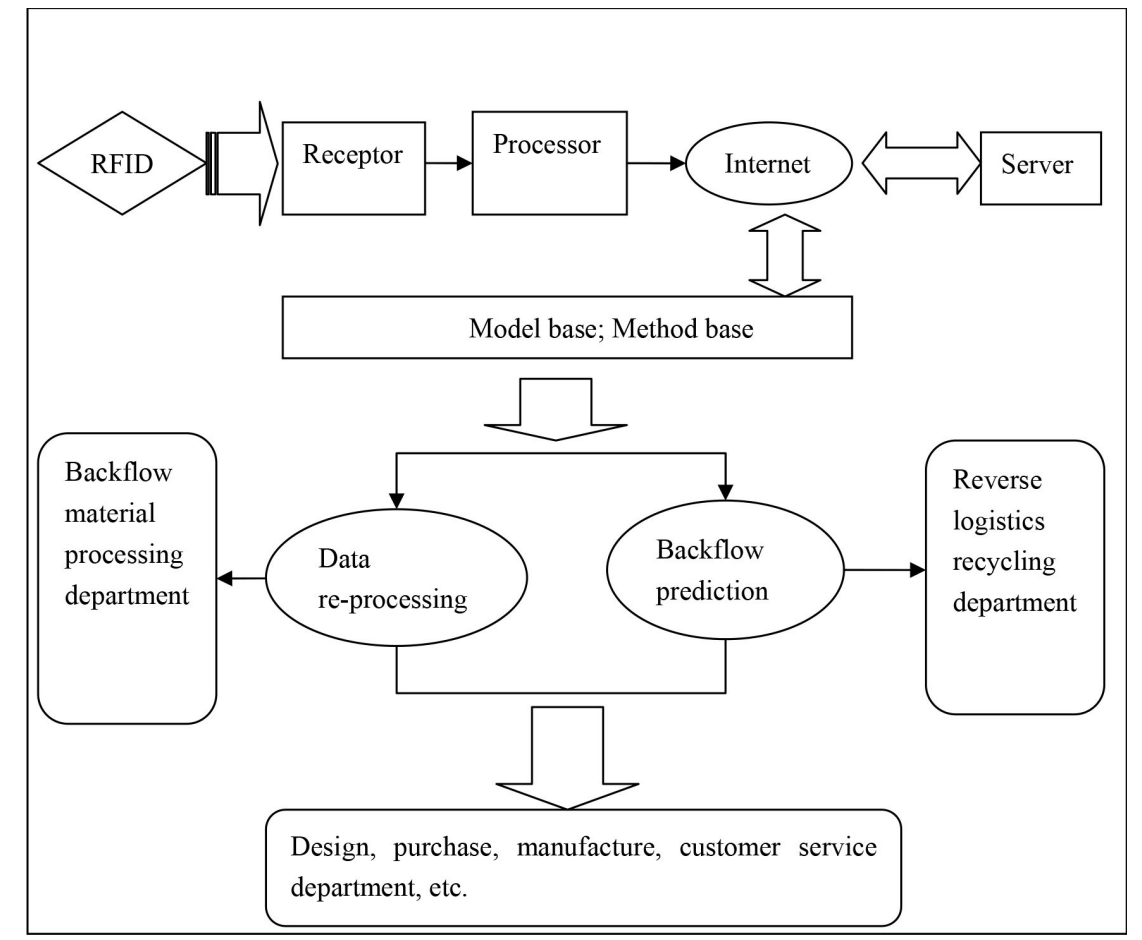

Figure 2. The information processing flow of the reverse logistics MIS based on the application of the Internet of Things technology

In production, the enterprise can record information of the product's components into the PML server either through traditional information recording method, or through RFID. When the product is away from the enterprise, relevant data is collected through the Internet of Things. If the main participators along the supply chain perform some operation to the product, the receptor will receive information through its radio frequency identification tag and transmit the information to the computer. Then the computer will use the Internet or Intranet to transmit the electronic product code (EPC) to the object naming service (ONS), which links itself with the PML server and will therefore store the information in it. Therefore, the information which has been stored in the PML server is what we call the product information database.

There is a great uncertainty in the return of reverse logistics backflow products, which brings about a big challenge to the reverse logistics management. Nevertheless, through analyzing 
the product's condition along the supply chain, we can make more accurate predictions about backflow data, and therefore increase initiative of logistics management and improve the management level. When the product returns to the reverse logistics management department, the electronic product code obtained by the RFID tag will locate relevant data through using the Intranet to drive concerning model and method bases. Then, the computer will transmit the EPC to the ONS and find the PML which records product data so as to acquire the data in need. Moreover, the model base will provide the backflow material processing department with backflow product re-processing data for the decision-making support. And, the system will carry out data mining in backflow prediction data and re-processing data at regular or irregular intervals and offer advice to design, customer service, and purchasing and manufacturing departments for their reference with an aim to promoting their business and consistently optimizing the close-loop supply chain system. It should be mentioned that in the reverse logistics MIS, the Internet of Things is a prominent component to guarantee the effective operation of the whole system flow.

\section{Constraints on the reverse logistics MIS based on the application of the Internet of Things technology}

Although there is obvious advantage of the reverse logistics MIS based on the Internet of Things over the traditional MIS, there are some constraints in its wide application. Major constraints are illustrated as follows:

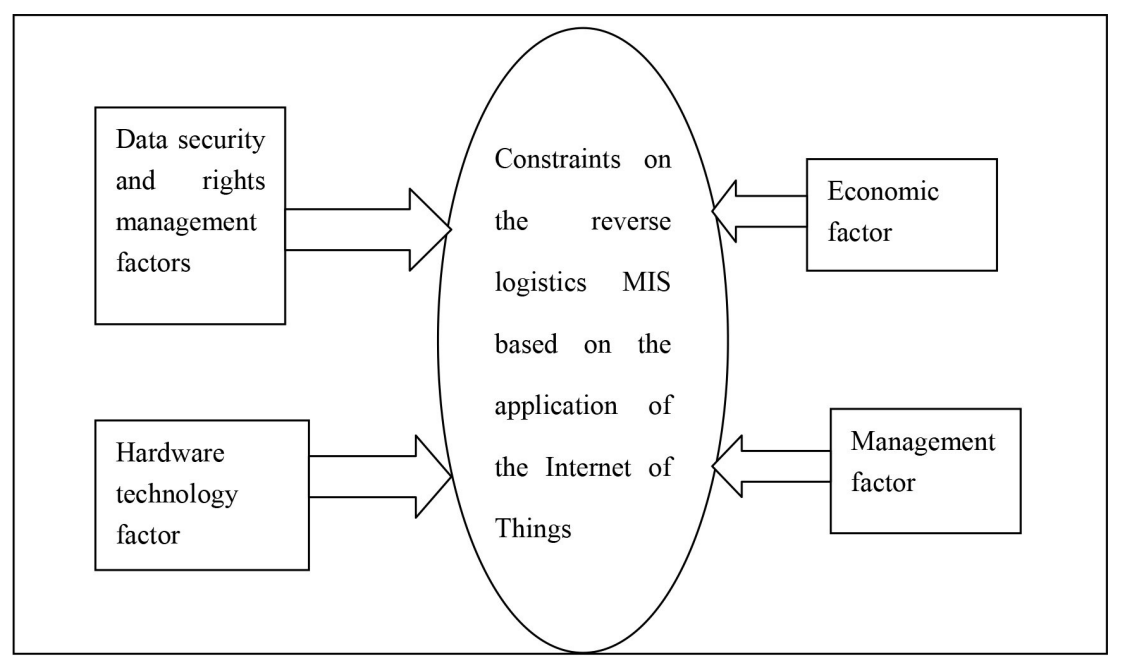

Figure 3. Constraints on the reverse logistics MIS based on the application of the Internet of Things technology

\subsection{Management constraint}

The reverse logistics involves many parts including final customers along the supply chain. How an enterprise acquires information through the Internet of Things depends on the external entity. Also, how to design a set of coordination mechanisms to activate the external entity, guarantee the accuracy and timely record of data, and even obtain return information in 
advance is a prerequisite for the sound operation of the system. In addition, due to concerns about commercial secrets and privacy by customers and downstream enterprises along the supply chain, they are suspicious of the radio frequency identification technology (RFID). In a word, all these problems should be solved with great attention to promote the Internet of Things.

\subsection{Economic constraint}

The Internet of Things plays an equally essential role in influencing the commerce with the Internet, but it calls for more investments. Not limited to IT enterprises, it is involved in more parts of the supply chain. For instance, a retailer company with more than 750 chain stores has once made a budget of building an Internet of Things for the company. It turned out that 25 million dollars should be invested in RFID technology in packing boxes, and 200 million dollars in item products. Because it is hard to reclaim the FRID tag, the actual costs may thus be much higher. Therefore, many enterprises have to bear a heavy financial burden in this regard.

\subsection{Hardware technology constraint}

Despite the Internet of Things' wide range of uses in product identification and information tracking, the reliability for such extensive uses can hardly be guaranteed. For the reverse logistics management, metal products like household appliances, automobiles and information technology products have high backflow value and therefore belong to the key reverse logistics industry, but they have rather low RFID rates. Besides, diverse standards of the Internet of Things technologies present another prominent obstacle.

\subsection{Data security and rights management constraints}

Because of information's fundamental influence on the whole reverse logistics operation, it is vital to guarantee that each independent legitimate user can have access to relevant information and process and store it. However, due to the complex ownership of the product during the whole life cycle, the traditional children key encryption system bears some disadvantages. Therefore, the fundamental issue lies in how to guarantee legitimate users' access and operation while preventing unauthorized access and illegal tampering so as to protect customers' privacy and guarantee the reliability of the reverse logistics business and decision-making information offered by this system.

\section{Conclusion}

Accurate and timely information lays the foundation of success for the reverse logistics management. It is indispensable form the support of the reverse logistics system to recycle, reuse and dispose of products. Having met the special requirements of information system by the reverse logistics, the reverse logistics MIS based on the application of the Internet is an 
essential developing model in the reverse logistics information management. Faced with some problems, it should be perfected in terms of technology and management. Moreover, apart from core enterprises' own efforts, collective collaboration with other enterprises, the government, the industry association and customers is required to tackle current problems.

Because the reverse logistics MIS is closely associated with e-commerce, core enterprises along the supply chain can make full use of electronic commercial means to build a transenterprise and trans-industrial e-commerce platform for the established reverse logistics MIS. Such a platform can not only contribute to their competitive advantages within the industry, but also bring about good social reputations as well as more obvious social benefits.

\section{References}

Ashayeri, J., \& Tuzkaya, G. (2010). Design of demand driven return supply chain for high-tech products. Journal of Industrial Engineering and Management, 4, 481-503.

Asif, R. (2011). Reverse Logistics: RFID the key to optimality. Journal of Industrial Engineering and Management, 4, 281-300. http://dx.doi.org/10.3926/jiem.2011.v4n2.p281-300

Daugherty, P.J., Richey, R.G., Genchev, S.E., \& Chen, H. (2005). Reverse logistics: superior performance through focused resource commitments to information technology. Transportation Research Part E: Logistics and Transportation Review, 41, 77-92. http://dx.doi.org/10.1016/j.tre.2004.04.002

Govindan, K., Palaniappan, M., Zhu, Q., \& Kannan, D. (2012). Analysis of third party reverse logistics provider using interpretive structural modeling. International Journal of Production Economics, 140, 204-211. http://dx.doi.org/10.1016/j.ijpe.2012.01.043

Jamshidi, M. (2011). 13 - Reverse Logistics. Logistics Operations and Management, 247-266. http://dx.doi.org/10.1016/B978-0-12-385202-1.00013-X

Kiritsis, D. (2011). Closed-loop PLM for intelligent products in the era of the Internet of things. Computer-Aided Design, 43, 479-501. http://dx.doi.org/10.1016/j.cad.2010.03.002

Lambert, S., Riopel, D., \& Abdul-Kader, W. (2011). A reverse logistics decisions conceptual framework. Computers \& Industrial Engineering, 61, 561-581. http://dx.doi.org/10.1016/j.cie.2011.04.012

Miorandi, D., Sicari, S., De Pellegrini, F., \& Chlamtac, I. (2012). Internet of things: Vision, applications and research challenges. Ad Hoc Networks, 10, 1497-1516. http://dx.doi.org/10.1016/j.adhoc.2012.02.016

Senthil, S., Srirangacharyulu, B., \& Ramesh, A. (2012). A Decision Making Methodology for the Selection of Reverse Logistics Operating Channels. Procedia Engineering, 38, 418-428. http://dx.doi.org/10.1016/j.proeng.2012.06.052 
Thierry, M., Salomon, M., Van Nunen, Jo. \& Van Wassenhove, L. (1995). Strategic issues in product recovery management. California Management Review, 37(2), 114-135. http://dx.doi.org/10.2307/41165792

Yanxia, C., \& Hui, Y. (2005). Study on Construction of Reverse Logistics Information System Oriented Return Management. Science \&Technology Progress and Policy, 12, 8-10.

Zhiduan, X. (2005). Research on the Flexibility in Logistic Systems. Chinese Journal of Management, 4, 441-445.

Journal of Industrial Engineering and Management, 2013 (www.jiem.org)

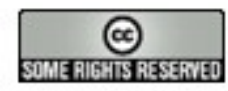

Article's contents are provided on a Attribution-Non Commercial 3.0 Creative commons license. Readers are allowed to copy, distribute and communicate article's contents, provided the author's and Journal of Industrial Engineering and Management's names are included. It must not be used for commercial purposes. To see the complete license contents, please visit http://creativecommons.org/licenses/by-nc/3.0/. 